\title{
Failure Assessment Methodologies for Pressure-Retaining Components under Severe Accident Loading
}

\author{
J. Arndt, H. Grebner, and J. Sievers \\ Reactor Safety Research-Barrier Effectiveness, Gesellschaft für Anlagen- und Reaktorsicherheit (GRS) mbH, \\ Schwertnergasse 1, 50667 Cologne, Germany \\ Correspondence should be addressed to J. Arndt, jens.arndt@grs.de
}

Received 16 December 2011; Accepted 27 March 2012

Academic Editor: Lluís Batet Miracle

Copyright () 2012 J. Arndt et al. This is an open access article distributed under the Creative Commons Attribution License, which permits unrestricted use, distribution, and reproduction in any medium, provided the original work is properly cited.

During postulated high-pressure core melt accident scenarios, temperature values of more than $800^{\circ} \mathrm{C}$ can be reached in the reactor coolant line and the surge line of a pressurised water reactor (PWR), before the bottom of the reactor pressure vessel experiences a significant temperature increase due to core melting. For the assessment of components of the primary cooling circuit, two methods are used by GRS. One is the simplified method ASTOR (approximated structural time of rupture). This method employs the hypothesis of linear damage accumulation for modeling damage progression. A failure time surface which is generated by structural finite element (FE) analysis of varying pressure and temperature loads serves as a basis for estimations of failure times. The second method is to perform thermohydraulic and structure mechanic calculations for the accident scenario under consideration using complex calculation models. The paper shortly describes both assessment procedures. Validation of the ASTOR method concerning a large-scale test on a pipe section with geometric properties similar to a reactor coolant line is presented as well as severe accident scenarios investigated with both methods.

\section{Introduction}

In face of severe accident scenarios with melted core material which occurred recently at Fukushima Daiichi and in 1979 at Three Mile Island-2 the integrity assessment of primary circuit components requires a special concern. A best estimate simulation of components under severe accident loading scenarios may be complex and time consuming (see second part of the paper). For the accomplishment of a simplified analysis concerning integrity of the components during a severe accident and especially the question which component fails first in framework of thermohydraulic analysis with system codes, an efficient method has been developed which will be described in the following chapters.

\section{Method ASTOR}

The method ASTOR is an easy applicable tool for fast estimation of failure times. Furthermore the reduced complexity enables the integration into thermohydraulic codes and may help to find results of structure mechanical properties which are required for coupled calculation of mechanical and thermohydraulic structure characteristics of primary circuit devices. Moreover the method ASTOR helps to determine the degree of structural damage after a history of load at the actual point of time. Therefore it is possible to determine the remaining durability of components under the assumption that the actual loads will continue at a constant level. The method ASTOR can be employed for failure time calculation without time intensive nonlinear structuremechanical analysis. The analysis requires a suitable failure time surface. The method ASTOR published already in [1] has been developed further to have more accurate results. In the following the method and the further development will be displayed. During a high-pressure core melt accident a transient temperature and pressure load will occur on the inner surface of a pipe (see Figure 1). The load can be characterized by a range of temperature and pressure. 


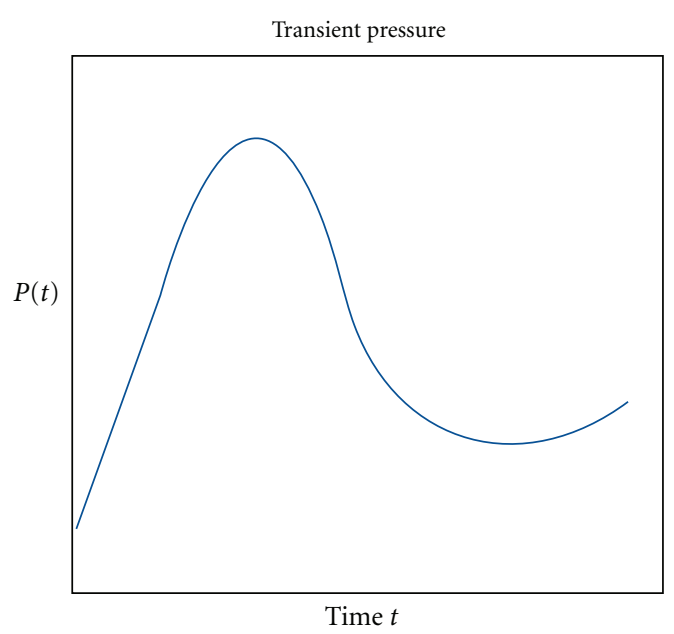

(a)

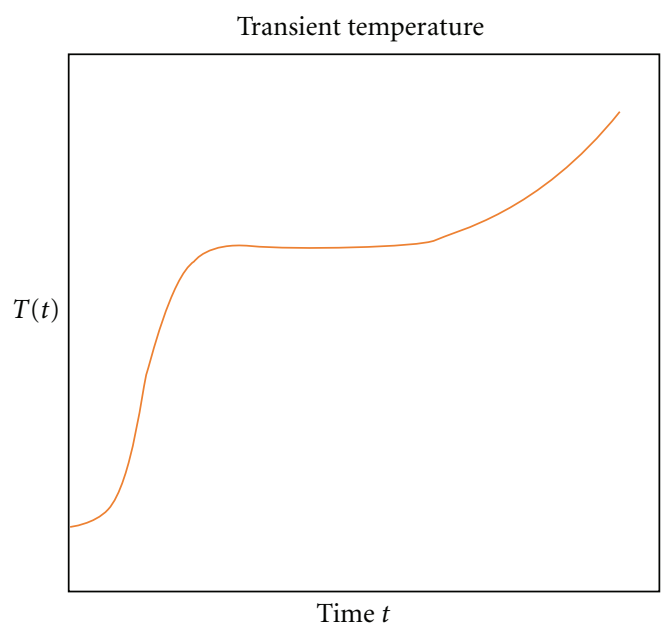

(b)

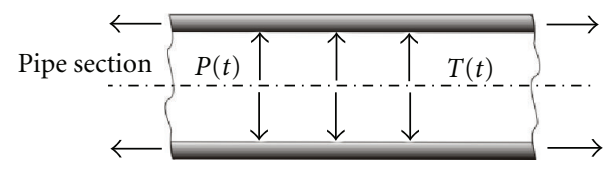

(c)

Figure 1: Transient loads on pipe.

Within the defined ranges, cascaded pressure steps and temperature steps are defined. Failure times of the pipe structure under combinations of pressure steps and temperature steps are determined by finite element analysis with the FEprogram ADINA [2].

Performing several numerical analyses of this kind to cover the ranges of temperatures and pressures to be expected in an accident yields a series of structural failure times which can be regarded as discrete pivots of a continuous failure time surface in the failure time-temperature-pressure space (see Figure 2). In the next step of the procedure, the failure time surface is used in connection with some damage accumulation hypothesis to predict the time to failure of the structure when subjected to loads which are varying in time. In these cases the characterizing parameters, that is, inner surface temperature and internal pressure, do change in the course of time. For each point of time which is characterized by a temperature and a pressure value, a damage increment can be calculated. The result of the summation of damage increments is a damage value $D(t)$. The failure can be assumed when the damage value $D(t)$ reaches a value of 1 or a smaller value if safety factors are included.

In the framework of further development, a timeconsuming method for the determination of failure surfaces has been developed. The chain of software modules consists of three modules. The first module provides a file structure and builds up the framework for forthcoming FE analysis and failure assessment. The module requires input data about FE geometry, material data, data about failure assessment, and information about the number of nodes of the failure surface. After each simulation run, a failure assessment is accomplished by a software module. Failure

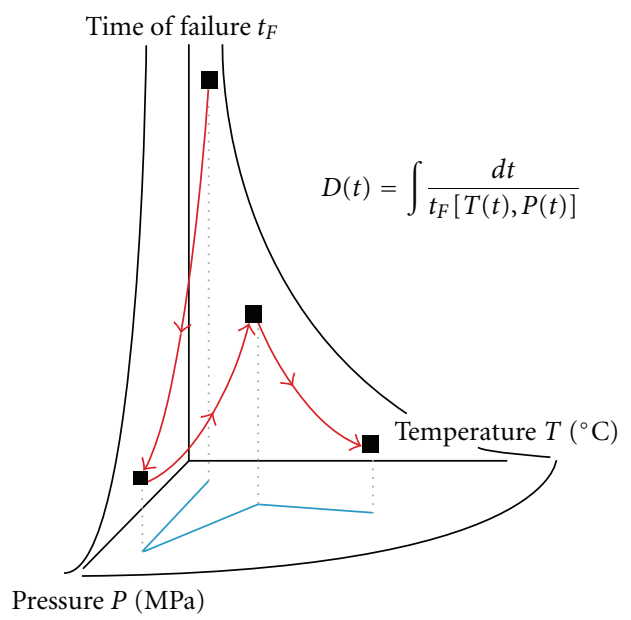

FIGURE 2: Linear damage accumulation hypothesis in ASTOR.

criteria for plastification and creep failure are used for failure assessment. After all simulation runs and failure assessments are accomplished, a final software module collects all available output and failure data for compilation of the input file for analysis by ASTOR.

\section{Material Data and Approximation of Creep Curves}

Bases for the temperature-dependent stress-strain-relations of the piping material steel $20 \mathrm{MnMoNi} 55$ used in German NPPs are data measured by the testing facility "Materialprüfungsanstalt (MPA)" of the University of Stuttgart 


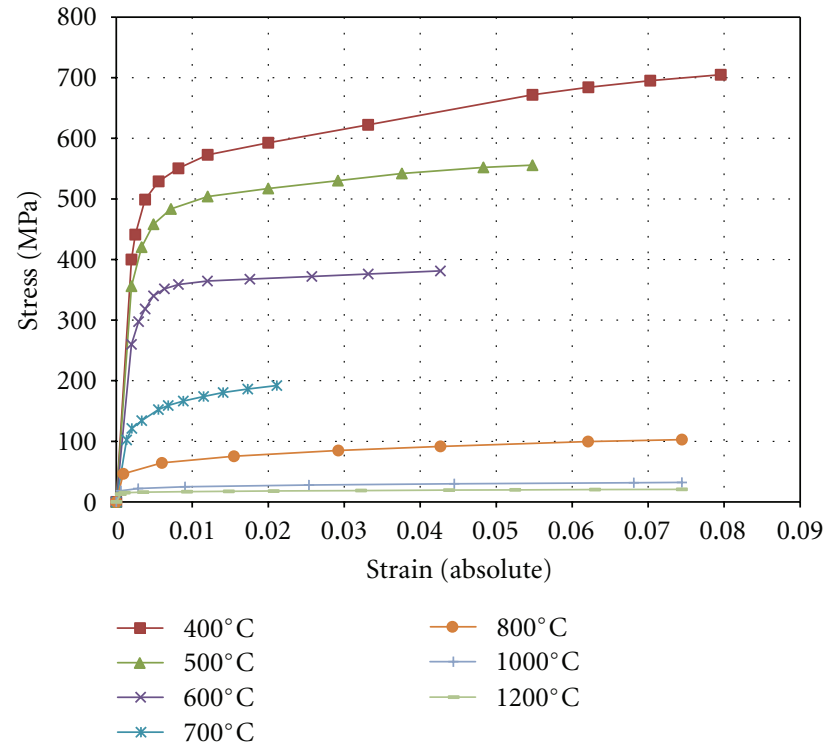

Figure 3: Steel $20 \mathrm{MnMoNi}$ 55: true stress-strain curves up to uniform elongation $\left(400^{\circ} \mathrm{C}-1200^{\circ} \mathrm{C}\right)$ derived from measured data.

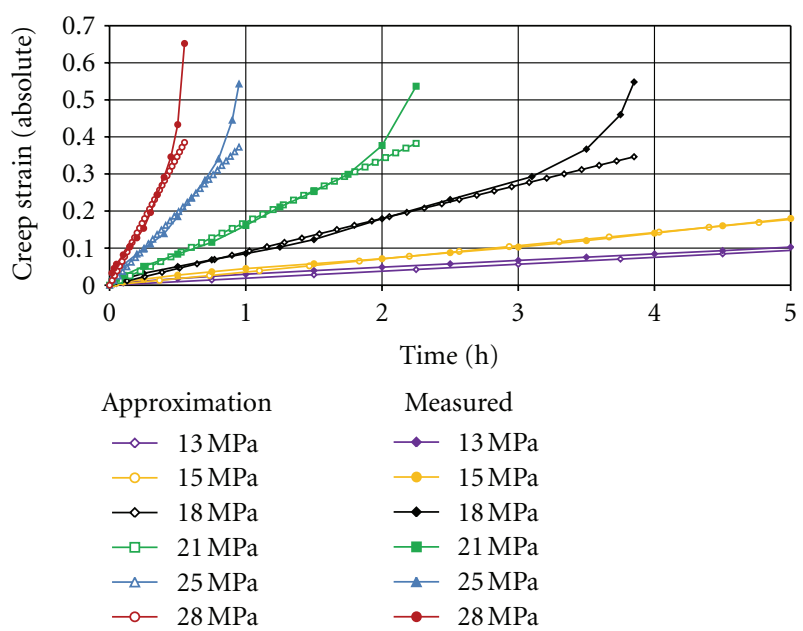

FIGURE 4: Linear approximation of measured creep curves (load controlled) of steel $20 \mathrm{MnMoNi} 55$ at $1000^{\circ} \mathrm{C}$.

$[3,4]$. Temperature-dependent stress-strain curves were derived for the temperatures up to $1200^{\circ} \mathrm{C}$ (Figure 3) to build up the basis for the material model of the FE-Program ADINA [2].

For the simulation of creep behaviour of components, the FE-codes usually include material models which describe the time dependence of creep strain with parameters stress and temperature. On the other hand the material characterisation is usually determined by load-controlled creep curves. Exemplary in Figure 4, the approximation of load-controlled creep curves for a temperature level of $1000^{\circ} \mathrm{C}$ is displayed.
For modeling of creep properties of the steel $20 \mathrm{MnMoNi}$ 55, a "Creep Law" of the FE program ADINA [2] was employed:

$$
e_{c}=a_{0} \sigma^{a_{1}} t^{a_{2}}
$$

with temperature- and stress-dependent parameters $a_{0}, a_{1}$, and $a_{2}$.

The steel $20 \mathrm{MnMoNi} 55$ does not show a pronounced primary creep phase. Therefore, the secondary phase, which is important for the progress of creep, can be approximated by a straight line determined by the stress- and temperaturedependent parameter $a_{0}$ for the slope, $a_{1}=0$, and $a_{2}=1$. The tertiary creep phases of the load-controlled creep curves are not considered because in that phase the stress level increases. According to this method, the approximated creep curves of the steel $20 \mathrm{MnMoNi} 55$ were computed based on a spreadsheet analysis with MS Excel.

\section{Failure Criteria}

Both failures due to plastification and due to creep are employed as failure criteria for an integrity assessment based on FE analysis. Due to the higher level of stresses and strains, failure at the inside of the pipe structure is considered. To predict the time to failure of a piping based on a FE analysis it is necessary to define criteria for failure. The analysis results are assessed concerning failure on basis of a strain criterion. An ADINA material model is employed which considers plastic strains as well as creep strains. The value of strain is determined by the temperature-dependent strength and the temperature/stress-dependent creep characteristic of the relevant material. As the uniaxial strain limit for plastification, the uniform elongation is considered. Based on calculations of large-scale creep experiments, the limit of uniaxial creep strain is determined by $60 \%$ of the creep failure strain of the uniaxial creep tests for a safety-related assessment [5]. Especially for the question which component of a primary circuit fails first, additionally an assessment concerning failure as a matter of fact is necessary. This kind of assessment employs a limit of uniaxial creep strain determined by $100 \%$ of the creep failure strain of the uniaxial creep tests. Figure 5 shows the temperature dependency of the uniaxial limit of creep strain for the $60 \%$ and the $100 \%$, criterion.

For consideration of multiaxial stress and strain states it is common practice to reduce the strain limits by division with a triaxial-factor TF which appears in the following form [6]:

$$
\mathrm{TF}=\frac{\left|\sigma_{1}+\sigma_{2}+\sigma_{3}\right|}{\sigma_{\text {effective }}}
$$

The stresses $\sigma_{1}, \sigma_{2}$ and $\sigma_{3}$ represent the principal stresses

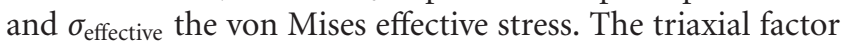
may reduce the strain limits for safety-related assessments significantly. 


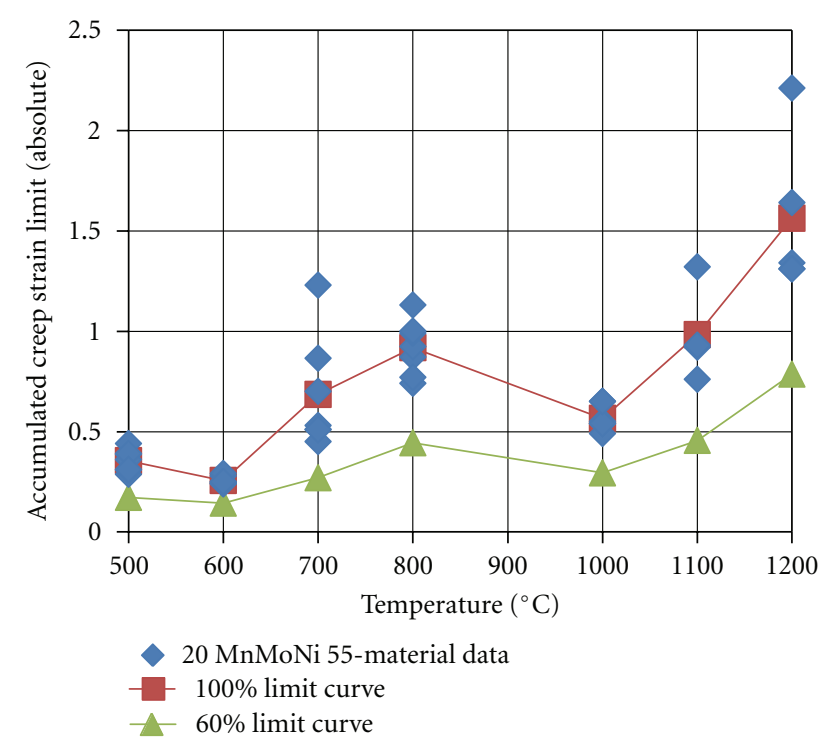

Figure 5: Steel 20 MnMoNi 55. Approach for definition of uniaxial creep limit.

\section{Simplified Finite Element Model of a Pipe Structure}

The abstraction from the pipe structure to the analysis model is displayed in Figure 6. The rotational symmetry of the pipe can be used for a reduction of the model into a $2 \mathrm{D}$ representation of the geometry. This helps to reduce computation times significantly which is obligatory in case of a high number of required computations.

Loads (forces and temperature) as well as boundary conditions are defined. Because of the rotational symmetry, it is possible to define loads and boundaries on lines. The temperature is defined as a homogenous temperature load on all elements.

\section{Failure Surface}

In the following a failure surface of a PWR reactor coolant line (RCL) with the geometry inner diameter $750 \mathrm{~mm}$ and wall thickness $62 \mathrm{~mm}$ is considered. In Figure 7 the calculated times of failure due to different constant temperature/pressure loads are summarized. A total of $740 \mathrm{FE}$ computations and failure assessments of a pipe structure were performed. There are 10 pressure steps from $0.5 \mathrm{MPa}$ up to $18 \mathrm{MPa}$. The temperature progression covers temperatures from $100^{\circ} \mathrm{C}$ up to $1300^{\circ} \mathrm{C}$. The correlation between increase of failure time by decrease of pressure and temperature is obvious. Failure times above a time limit of $40000 \mathrm{~s}$ are not considered. Exemplary the load steps of 0.5, 2, 6, 10, 14, and $18 \mathrm{MPa}$ are displayed. The failure time surface is considered as the surface which is spanned by the peaks of the columns.

\section{Component Test and Simulation}

For validation of the employed FE simulation and the failure assessment, procedure test data of a component test [7] are employed. The question of the short-term creep behavior at high temperatures was in the focus of this experimental investigation. The endurance and the fracture opening behavior of the reactor coolant piping were determined. For verification of the results from small specimen tests, a component test on a section of piping was carried out. The reactor steel $20 \mathrm{MnMoNi} 55$ was used as the test material. The conduct of this test was to simulate specific accident conditions; under a constant internal pressure of about 16.6 MPa using air as the pressurizing medium, the vessel was heated from outside to about $730^{\circ} \mathrm{C}$ to determine the time to failure (see Figure 8). The component test was conducted on a pipe of about $8 \mathrm{~m}$ total length closed at its ends by dished heads. The actual test pipe section which was welded into the center had a length of $2700 \mathrm{~mm}$, an internal diameter of $700 \mathrm{~mm}$, and a wall thickness of $47 \mathrm{~mm}$. The whole test assembly was freely suspended by means of welded-on lugs. Pronounced plastic deformation commenced about $780 \mathrm{~s}$ before failure, that is, about $320 \mathrm{~s}$ after begin of the holding phase at a temperature of about $720^{\circ} \mathrm{C}$. Failure occurred by the appearance of a longitudinal crack which after reaching the circumferential weld seam of one of the two extension pipes was deflected into the circumferential direction. A thermal FE analysis by ADINA [2] is accomplished to obtain the temperature distribution of the structure. The output of thermal FE analysis is used as temperature input data for the following implicit FE analysis. A simulation model with the geometrical properties of the test pipe was employed for a FE simulation with ADINA. The reduced 2D model revealed in Figure 6 was employed with modified dimensions. The test pipe has an inner diameter of $D_{i}=700 \mathrm{~mm}$ and a thickness $t=47 \mathrm{~mm}$. A failure criterion which employs the $60 \%$ of the creep failure strain of the uniaxial creep tests reduced by the calculated stress triaxiality factor was used for a safety-related assessment (see Figure 9). The used criterion predicts a failure at $12470 \mathrm{~s}$ which is very close to the failure time of the test $(12469 \mathrm{~s})$. The results of the component test simulation have been presented on SMiRT 21 [8].

\section{Simulation of Severe Accident Scenario}

In the following section the results of an FE-based failure assessment and an ASTOR failure analysis for an RCL loaded during a severe accident scenario are compared. Due to an assumed station blackout scenario of a PWR, molten core material in the reactor pressure vessel-lower head (RPV-LH) may cause catastrophic consequences. The time of failure of the RCL is of special concern because a failure before the RPV-LH's failure may enable a significant pressure decrease. In the following a reactor coolant line, as considered in Section 6 is assessed under high-pressure and temperature conditions. Table 1 gives an overview of the relevant simulation runs and the employed failure assessment criteria. 


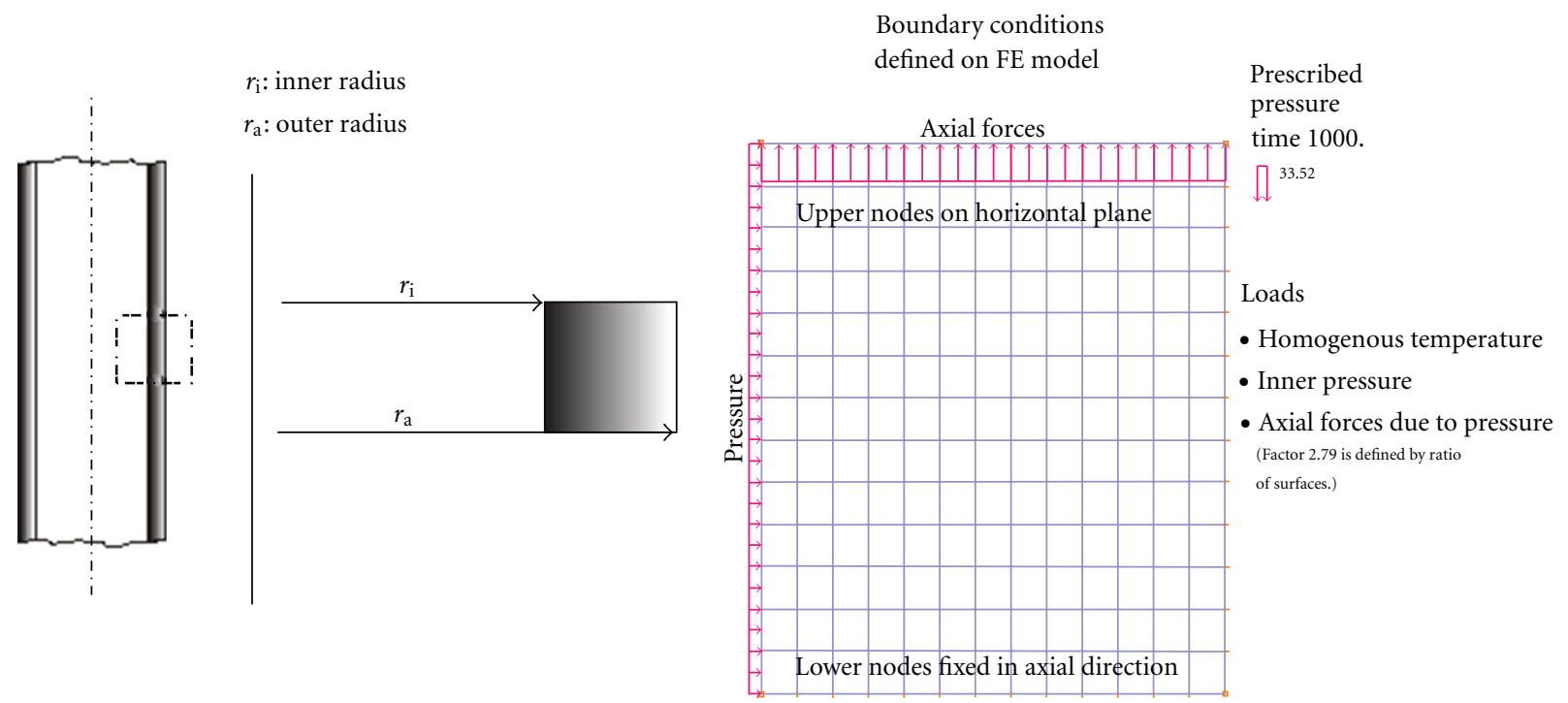

FIGURE 6: 2D representation of pipe structure, dimensions, loads, and boundary conditions.

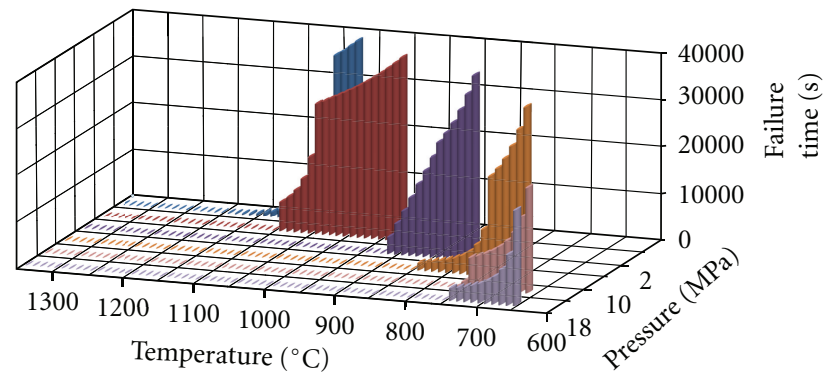

FIGURE 7: Failure time diagram for a RCL of 20 MnMoNi 55.

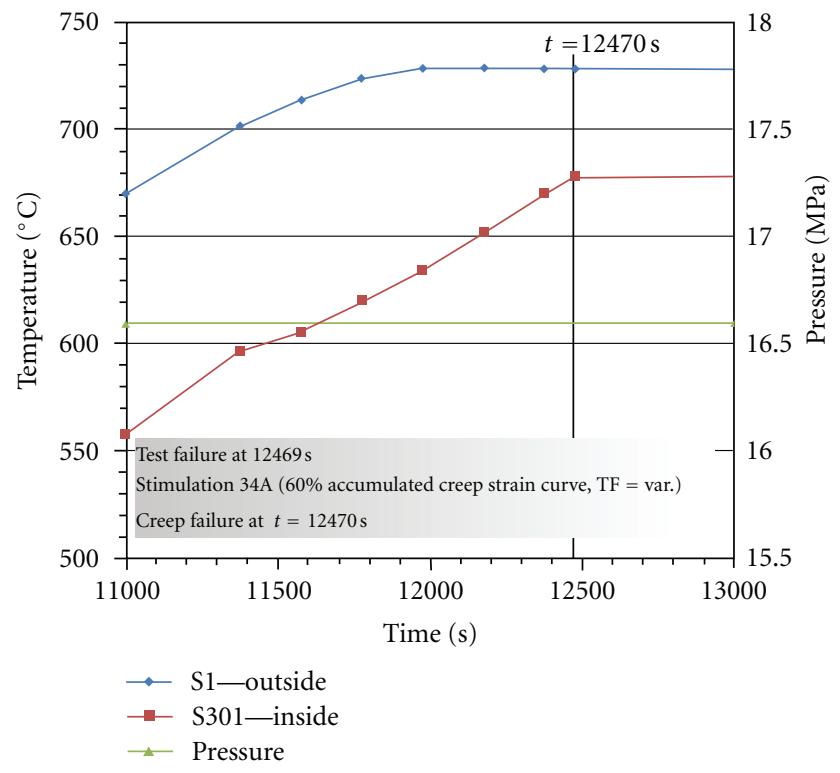

Figure 8: Loading conditions in the test pipe.

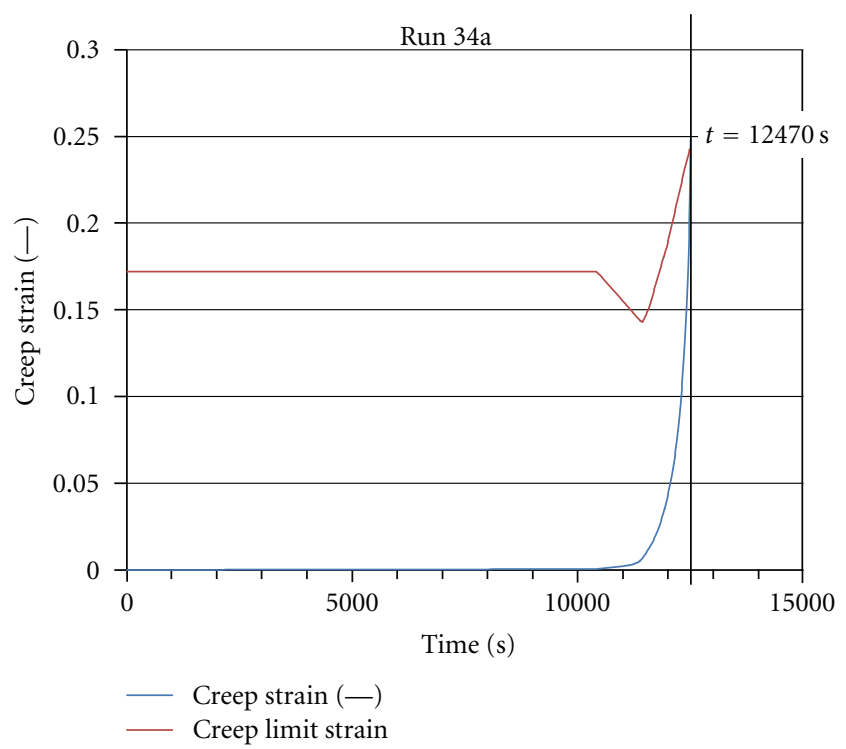

FIgURE 9: Accumulated creep strain and strain limit curve (failure at $12470 \mathrm{~s})$.

Figure 10 reveals the temperature and pressure progression of the RCL calculated with MELCOR [9]. The temperatures reach a maximum of $969^{\circ} \mathrm{C}$ at $66280 \mathrm{~s}$. The pressure oscillates at $12 \mathrm{MPa}$ with an amplitude of $0.8 \mathrm{MPa}$. For simplification purposes up to a time of $40,000 \mathrm{~s}$, the maximum value of the amplitude is assumed as input data for ADINA. This simplification is only applied at low temperature levels $\left(<500^{\circ} \mathrm{C}\right)$, where no significant failure progression is expected.

In Run A the creep strains meet the limit strain prior to the plastic strains based on the safety-related failure criterion with consideration of the triaxial stress factor after about 
TABLE 1: Failure assessment criteria.

\begin{tabular}{|c|c|c|}
\hline Run \# & $\begin{array}{l}\text { Creep failure } \\
\text { assessment }\end{array}$ & Plastic failure assessment \\
\hline A & $\begin{array}{l}60 \% \text { limit curve (see } \\
\text { Figure 5) with } \\
\text { variable TF }\end{array}$ & $\begin{array}{l}\text { Uniform } \\
\text { elongation/variable TF }\end{array}$ \\
\hline B & $\begin{array}{l}100 \% \text { limit curve (see } \\
\text { Figure } 5 \text { ) with } \\
\text { constant } \mathrm{TF}=1\end{array}$ & $\begin{array}{l}\text { Uniform } \\
\text { elongation/constant } \mathrm{TF}\end{array}$ \\
\hline
\end{tabular}

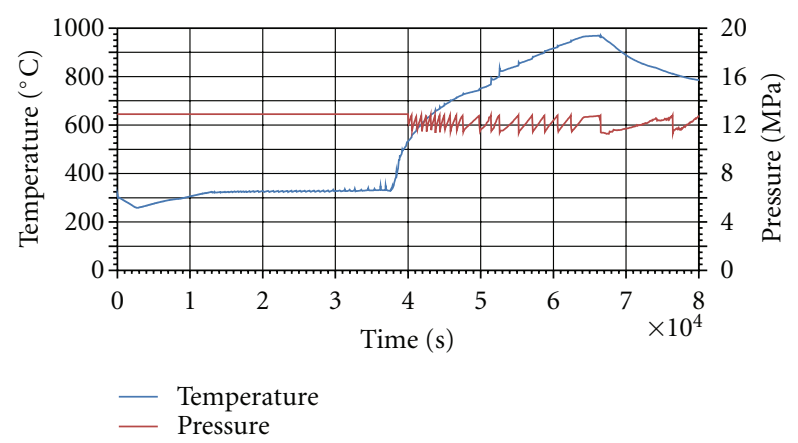

Figure 10: Temperature and pressure progression.

47471 s (see Figure 11). From safety-related point of view failure due to creep cannot be excluded after that time.

In Run B after about $47500 \mathrm{~s}$, a strong increase of the plastic strains can be observed. The calculated plastic strains meet the criterion for failure as a matter of fact after about $47656 \mathrm{~s}$.

Figure 12 displays the summation of damage increments within a calculation with ASTOR. For failure assessment, different damage values are considered. An accumulated damage $D=1.0$ is fulfilled at a time of $49118 \mathrm{~s}, D=0.5$ is reached at $47750 \mathrm{~s}$ and $D=0.4$ at $46760 \mathrm{~s}$.

Figure 13 summarizes the failure times of all failure assessments. As one can see, the time gap between the safetyrelated assessment and the failure; as a matter of fact based on FE analysis can be estimated by about $185 \mathrm{~s}$. The failure times determined by ASTOR vary from $46760 \mathrm{~s}(D=0.4)$ to $49118 \mathrm{~s}(D=1.0)$. The investigation shows that ASTOR results for damage values of about $0.4-0.5$ are close to the FE results. Further work with different loading scenarios should be performed to confirm this conclusion. The results of the severe accident simulation have been presented on SMiRT 21 [8].

\section{Detailed Thermohydraulic and Structure Mechanic Calculation of a Severe Accident Scenario}

As a further example, the integrity of components in the primary circuit of a PWR loaded by a core-melt scenario with remaining high-pressure in the primary cooling circuit has been investigated with a complex analysis model. Thermohydraulic evaluations for this case show that the reactor pressure vessel (RPV) bottom, the main coolant lines (MCL),

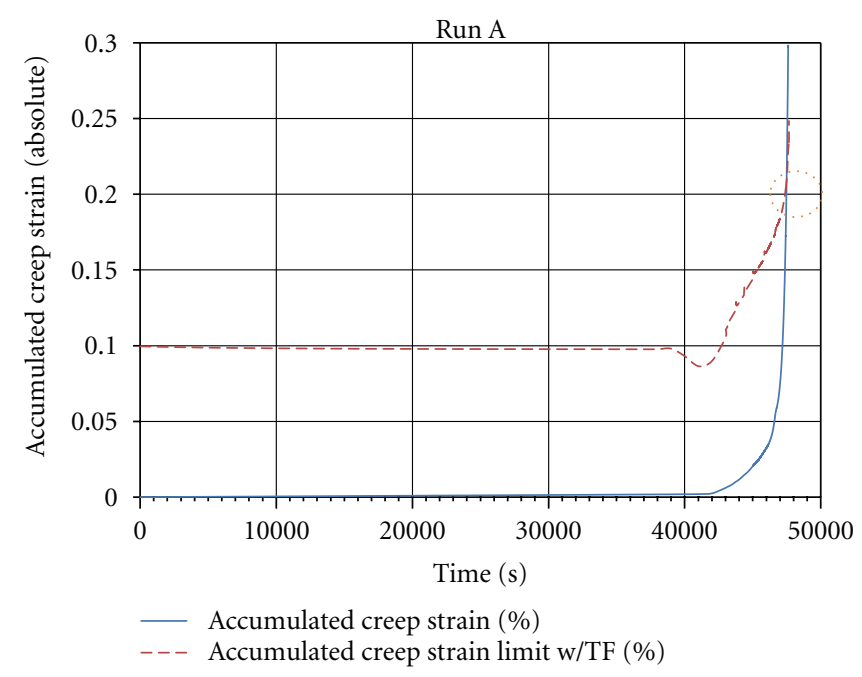

(a)

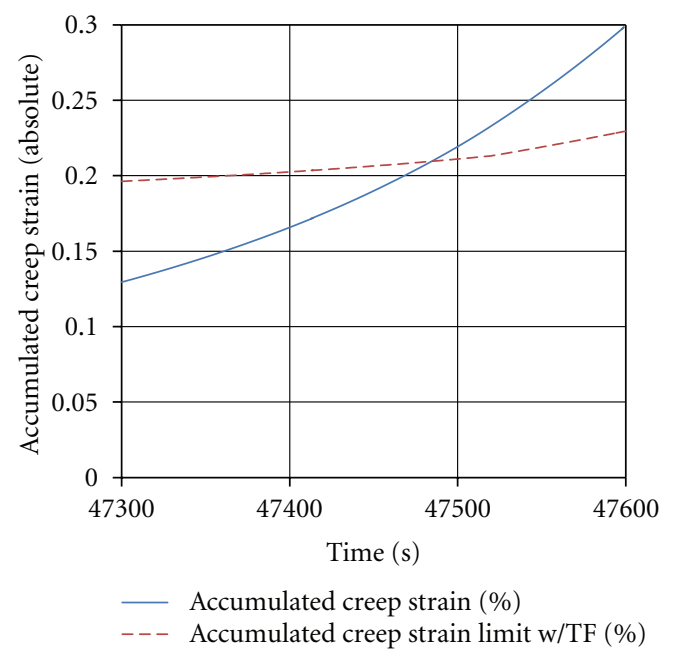

(b)

FIGURE 11: Accumulated creep strain and strain limit curve (failure at $47471 \mathrm{~s}$ ): overview and detailed view.

and the surge line can reach temperatures above $800^{\circ} \mathrm{C}$. A main aim of the study was to clarify whether the pipe lines will fail earlier than the RPV bottom or vice versa.

To estimate the failure temperatures and times, structure mechanic calculations with the FE code ADINA [2] were performed with load assumptions concerning internal pressure and component temperatures which are gained by Thermohydraulic calculations.

9.1. Essential Results of Thermohydraulic Calculations . For the Thermohydraulic calculation of the assumed accident scenario, the program MELCOR [9] was used. The complete primary circuit of a PWR was simulated. Some essential results of temperature and pressure distributions are presented in Figures 14 and 15.

9.2. FE Model for Structure Mechanic Calculations. For the FE calculations with ADINA [2], a model of the surge-line loop 


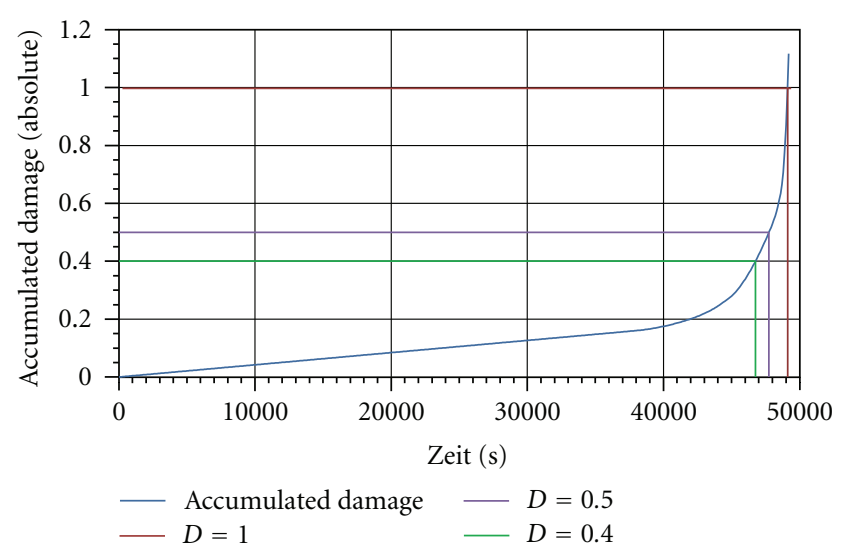

FIgURE 12: Summation of damage increments (ASTOR).

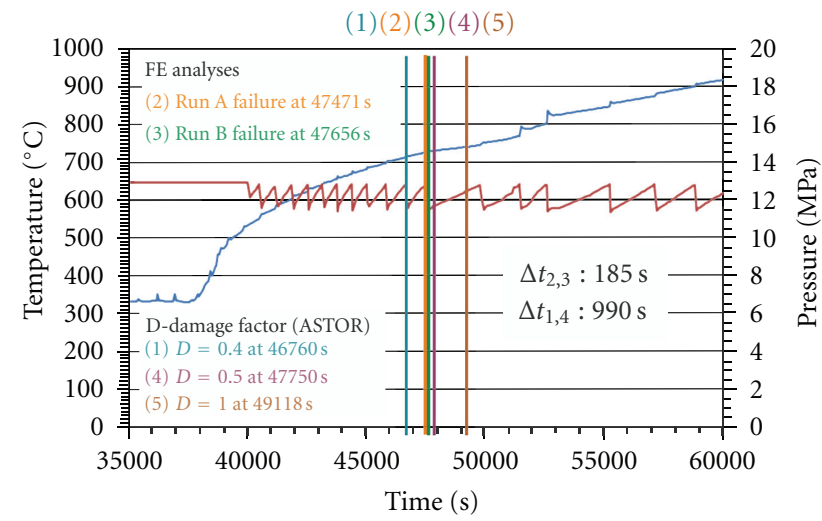

FIGURE 13: Failure times and load progression.

of a PWR was used. The model shown in Figure 16 was built up during research projects at GRS; see for example, [10]. It also contains feedwater and steam line from steam generator to the containment penetration.

As the model is loaded by temperatures up to nearly $1000^{\circ} \mathrm{C}$, corresponding high-temperature material data have to be used. For the ferritic parts, the stress-strain curves shown in Figure 3 are used. Similar data are provided for the austenitic part of the model (surge line).

As mentioned already, the load functions for the FE model concerning the wall temperatures of the components and the internal pressure are delivered by results of MELCOR calculations (accident scenario "total station blackout"). At 35 positions of the FE loop model, the temperature inside and outside the wall was evaluated. The temperature values between these positions are gained by interpolation. Also the temperature values in the middle of the wall were found by interpolation.

9.3. Estimation of Time of Failure. As described before a strain-based approach is used for the failure assessment. From the material side, the temperature-dependent strain value at uniform elongation is considered. To take constraint effects into account, this value is divided by the stress

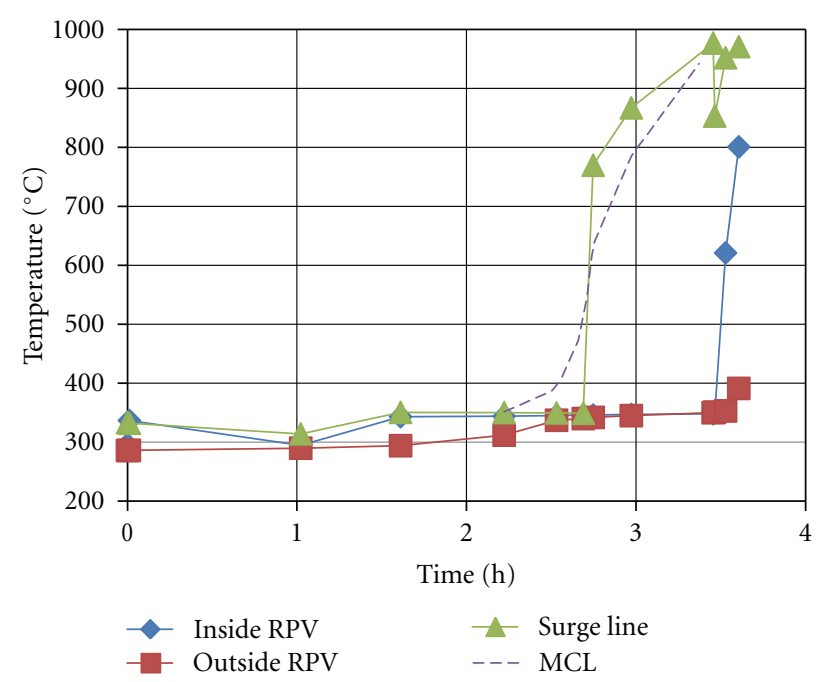

FIGURE 14: Temperatures versus transient time for different positions.

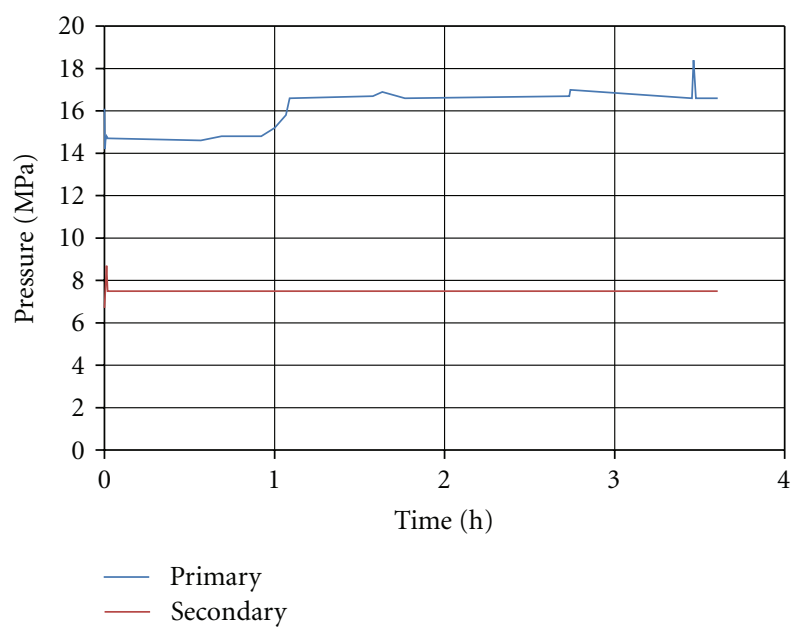

Figure 15: Pressures versus transient time for primary and secondary circuit positions.

triaxiality factor TF as defined before. If the calculated accumulated effective plastic strain exceeds the strain limit at some integration point, the failure of the component is assumed in the sense of a safety-related assessment. Furthermore an assessment concerning failure as a matter of fact is performed with $\mathrm{TF}=1$.

9.4. Selected Results of the Structure Mechanic Calculation. To show how the estimation of failure time is carried out, two selected evaluations are shown in Figures 17 and 18. The first one is for a typical integration point in the main coolant line (hot leg) between RPV and steam generator; the second one is an integration point in the surge line.

The intersection points of eg/TF and ep deliver the failure times of a safety-related assessment. For the MCL this gives a failure time of about $3.1 \mathrm{~h}$ of the transient time. An assessment of the MCL with $\mathrm{TF}=1$, that is, failure as a matter 


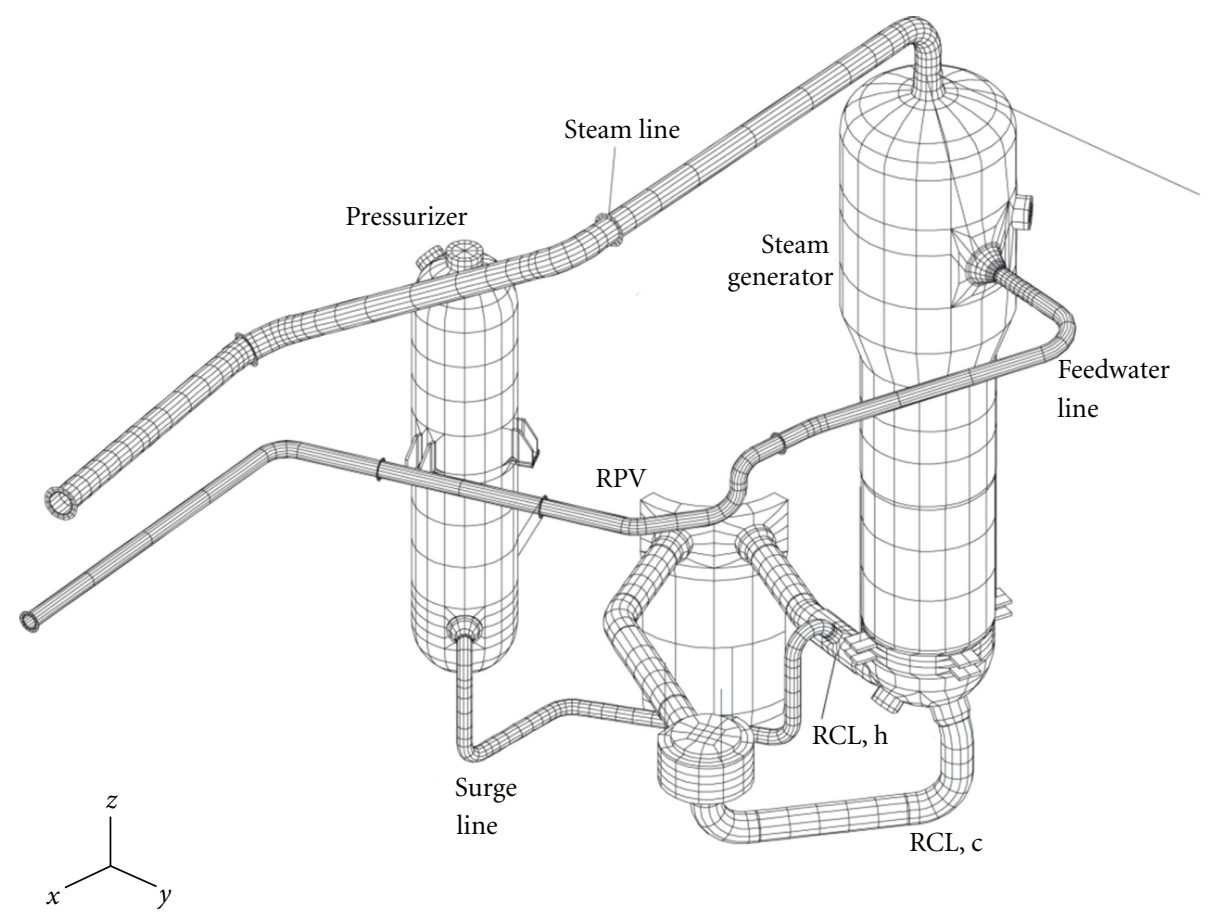

FIGURE 16: FE model of the coolant loop including surge line and pressurizer.

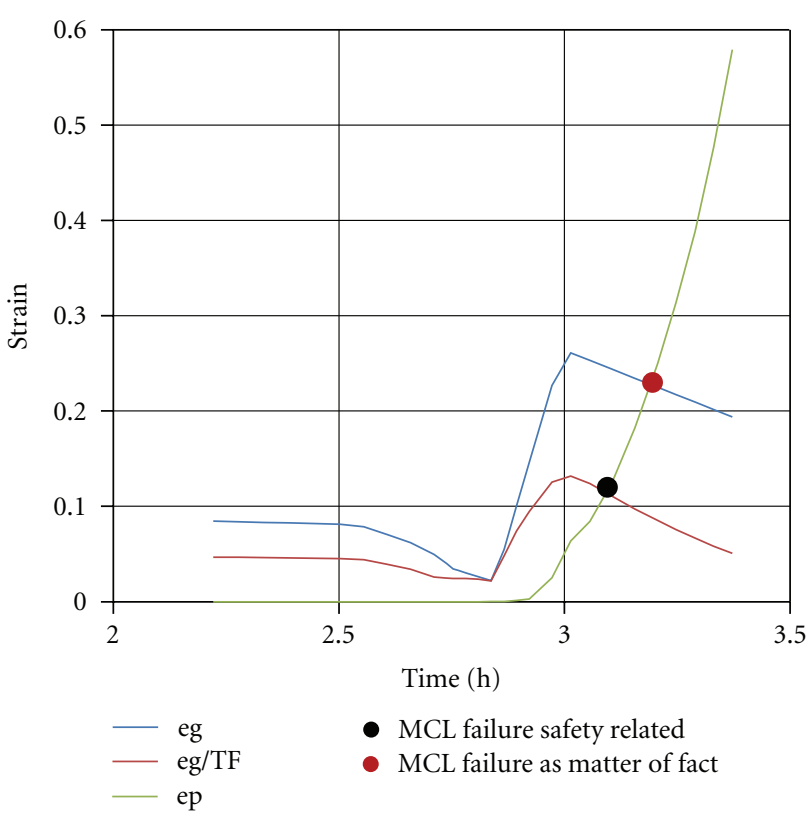

FIGURE 17: Structure mechanic assessment for a typical integration point in the MCL (eg: strain at uniform elongation concerning the respective temperature, eg/TF: strain at uniform elongation divided by stress triaxiality factor, ep: accumulated plastic strain).

of fact, gives a failure time of about $3.2 \mathrm{~h}$. For the surge line a failure time of about $3.35 \mathrm{~h}$ is found based on a safety related assessment.

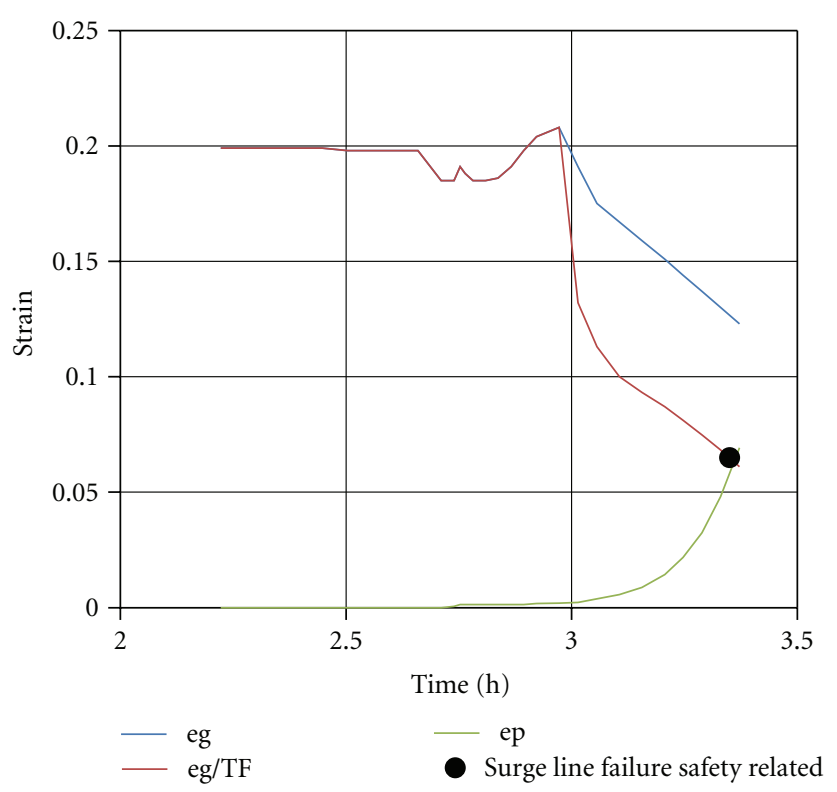

FiguRE 18: Structure mechanic assessment for a typical integration point in the surge line (eg: strain at uniform elongation concerning the respective temperature, eg/TF: strain at uniform elongation divided by stress triaxiality factor, ep: calculated accumulated plastic strain).

Additionally Figure 19 presents times and temperature values at failure for MCL and surge line together with the transient temperatures calculated by MELCOR. 


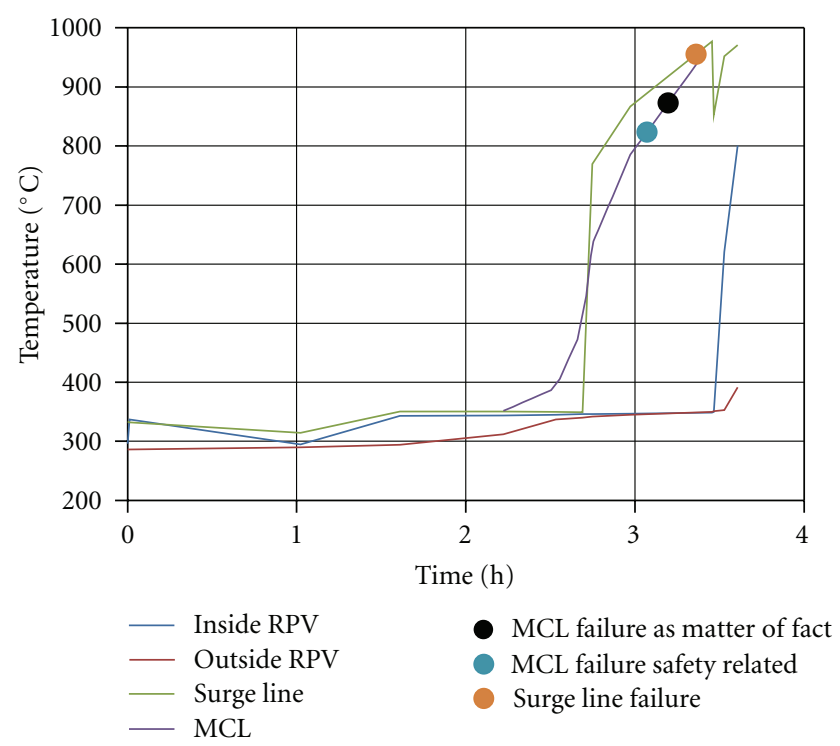

Figure 19: Temperatures versus transient time for different positions together with times and temperatures of failure for MCL and surge line.

The steep increase of the RPV temperature starts at about $3.5 \mathrm{~h}$ transient time. It may be concluded that failure of the MCL is expected about $0.3 \mathrm{~h}$ before the temperature increase of the RPV starts. Creep effects have not been considered in this analysis, but they would contribute to an increase of the time difference mentioned before.

\section{Conclusions}

The comparison of failure times of a large-scale creep test and FE analysis confirms that the FE analysis method including the used failure criterion is a best estimate method.

The method ASTOR enables a fast estimation of failure times and can be integrated into the framework of thermohydraulic system analysis programs. The application of ASTOR is limited to the boundary conditions concerning pipe geometry, material data, and type of loading used for generation of the failure surface. An uncertainty of the calculated failure times exists but can be constrained by a decrease of the assumed damage limit value. The comparison of ASTOR results with more rigorous FE analysis results requires verifications to quantify error bands. The results of the investigation show that the time of failure is strongly dependent on the changing stress level during the transient loading and the temperature-dependent material properties characterizing plastification as well as the temperature/stressdependent material properties characterizing creep of the piping material. Also the uncertainty of the employed material data has to be mentioned. The required creep data are derived from load-controlled creep curves by use of a simplification method. Because the material creep data are only available for a limited range of stresses and temperatures, the FE code may use extrapolated data by trend analysis outside the range.
An accident with a core melt scenario under highpressure loading caused by a station blackout is used as an example for an estimation of failure times by complex thermohydraulic and structure mechanic calculations. The thermohydraulic calculations with MELCOR show that in the course of the transient temperature values of above $800^{\circ} \mathrm{C}$ are reached at several positions of the cooling circuit. Using the temperatures and pressures evaluated by MELCOR as input for the structure mechanic calculation with ADINA, results in terms of stresses and strains were gained for the primary coolant loop under the accident scenario is considered. Using a strain-based failure assessment, failure times were estimated for the relevant positions of the loop model. While the temperatures in the RPV bottom are still relatively low, plastic strains in the main coolant and surge line reach limit values. Therefore it might be concluded that the MCL fails earlier than the RPV bottom. Since the failure times of the different positions do not differ very much, more studies might be necessary for the quantification of uncertainties. Especially the influence of creep could be considered more precisely. Finally it has to be pointed out that here only a special accident has been treated. Other accidents with different temperature and pressure transients might give other failure sequences.

Dependent on the required accuracy of the time of failure of a pipe, three failure assessment methods are accomplishable:

(i) ASTOR (useful for implementation in system codes, limited applicability, limited accuracy, extensive concerning generation of failure surfaces),

(ii) FE analysis with simplified FE model (flexible concerning application, limited applicability concerning complexity, high accuracy),

(iii) Complex FE analysis model with consideration of interaction between components [10] (extensive concerning generation of analysis model, flexible concerning application, high accuracy).

\section{Abbreviations}

ADINA: Automatic dynamic incremental nonlinear analysis

ASTOR: Approximated structural time of rupture

FE: $\quad$ Finite element

MCL: $\quad$ Main coolant line

MELCOR: Thermohydraulic system code

NPP: $\quad$ Nuclear power plant

PWR: $\quad$ Pressurized water reactor

RCL: $\quad$ Reactor coolant line

RPV-LH: Reactor pressure vessel-lower head

TF: $\quad$ Triaxiality factor.

\section{Acknowledgments}

The work has been predominantly performed in the framework of the Reactor Safety Research Program of the German Federal Ministry of Economics and Technology. The support of parts of the work by the German Federal Ministry for 
the Environment, Nature Conversation and Nuclear Safety is also acknowledged.

\section{References}

[1] P. Eisert, P. Gruner, and W. Kuntze, "Estimation of PWR lower head failure times using the method ASTOR".

[2] ADINA (Automatic Dynamic Incremental Nonlinear Analysis), "Version 8.7, Theory and Modeling Guide," ADINA R\&D, 2010.

[3] "Determination and modeling of material behavior of reactor steels under multiaxial loading in the temperature range from $400^{\circ} \mathrm{C}$ up to $1000^{\circ} \mathrm{C}$," Reactor Safety Research Project 1501 010, MPA-Stuttgart, 1999.

[4] "Description of the short-time rupture behavior at temperatures up to $1200^{\circ} \mathrm{C}$ exceeding usual design on the basis of damage mechanism," Reactor Safety Research Project 1501 257, MPA-Stuttgart, 2005.

[5] P. Eisert, P. Bachmann, and J. Sievers, "Further development of the structure mechanic analysis methods for the determination of the creep behaviour of components," Final Report on Research project RS 1115, GRS-A- 3104, 2003.

[6] F. Ju and T. Buttler, "Review of proposed failure criteria for ductile materials," NUREG/CR 3644, 1984.

[7] K. Maile, A. Klenk, V. Obst, and D. Sturm, "Load carrying behaviour of the primary system of PWRs for loads beyond the design limits. Part 2: creep and failure behaviour of a piping section under internal pressure and high temperature," Nuclear Engineering and Design, vol. 119, no. 2-3, pp. 131-137, 1990.

[8] J. Arndt and J. Sievers, "Failure assessment methodology for piping under high temperature and pressure due to creep and plastification," in Proceedings of the 21st International Conference on Structure Mechanics in Reactor Technology (SMiRT '21), New Delhi, India, November 2011.

[9] K. B. Cady, V. K. Dhir, and R. J. Witt, "Peer review of models for lower vessel head heat transfer and larson-miller failure criterion proposed for implementation into MELCOR," ERI/NRC 94-202, 1994, MELCOR 1.86 Reference Manual (NUREG/CR-6119, Vol. 2, Rev. 3).

[10] H. Grebner and J. Sievers, "Limit load of a PWR coolant loop for a hypothetical core melt scenario with high temperature and high pressure," 27. MPA-Seminar, Stuttgart, Germany, October 2001. 

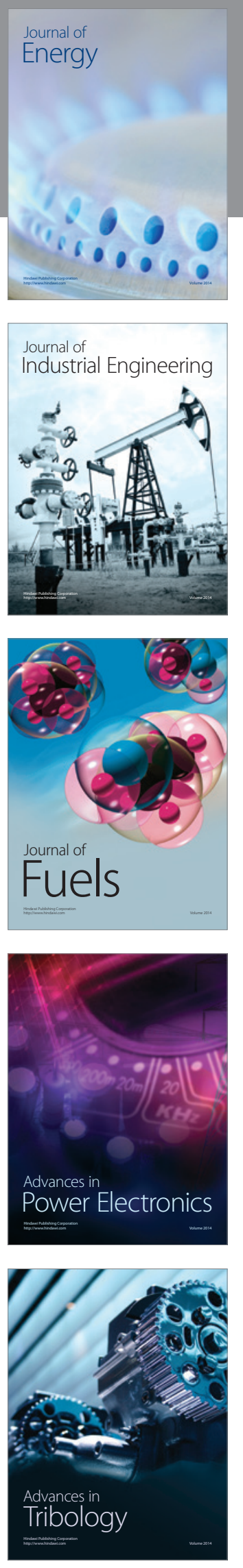
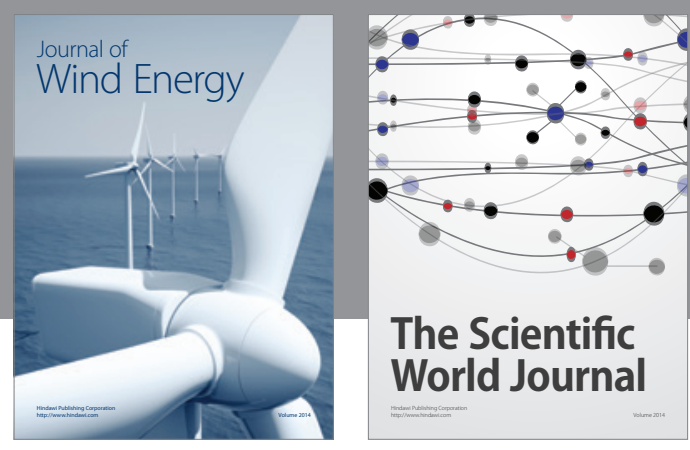

The Scientific World Journal

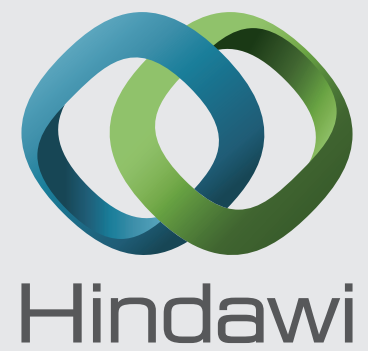

Submit your manuscripts at http://www.hindawi.com
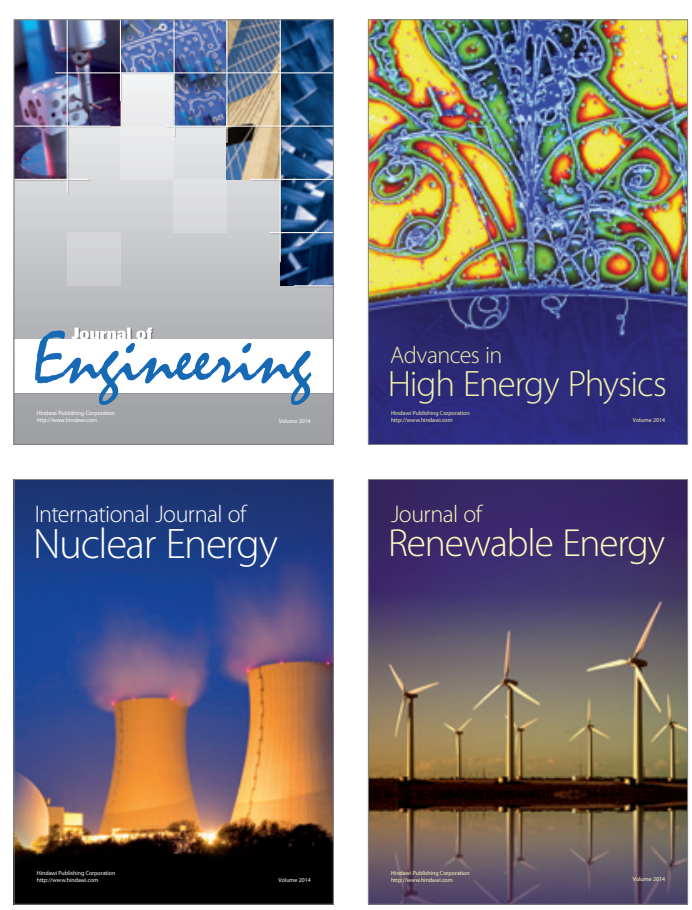

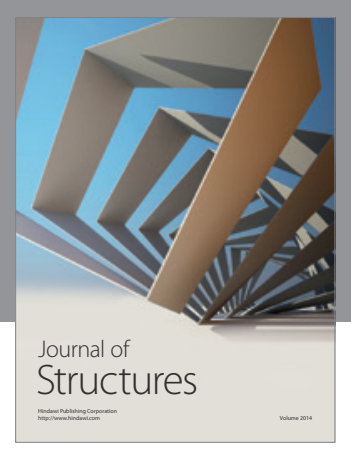

Rotating
Mechinery
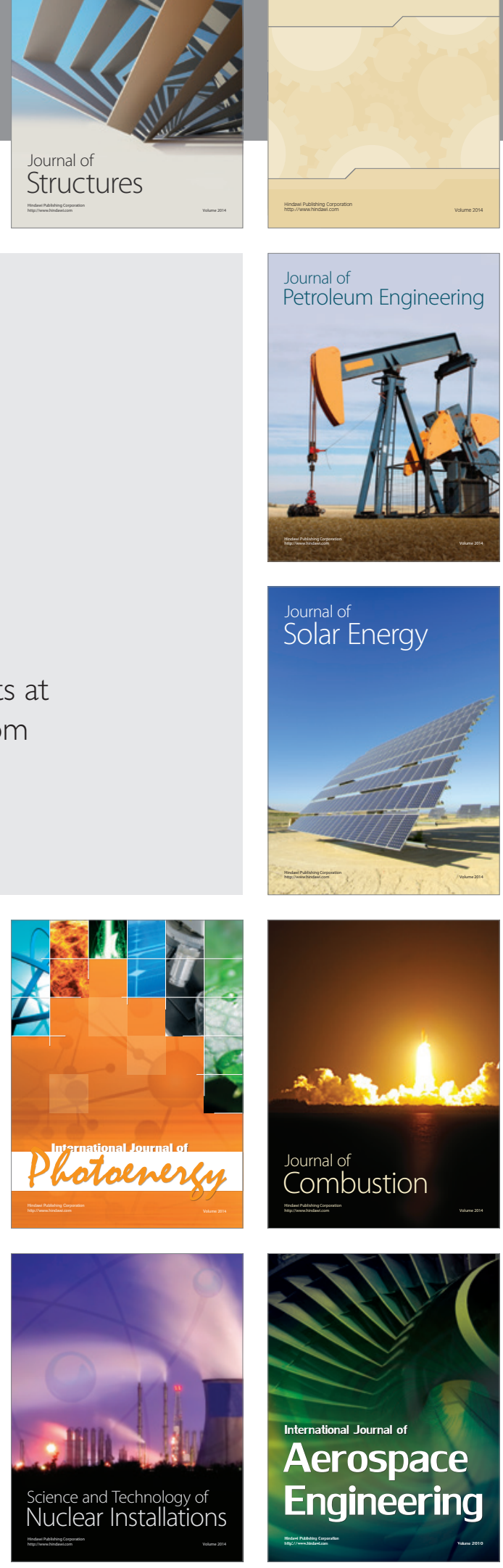